\title{
Cancer Research in the Arab World
}

\section{A review of publications from seven countries between 2000-2013}

*Randah R. Hamadeh, ${ }^{1}$ Saif M. Borgan, ${ }^{2}$ Abla M. Sibai ${ }^{3}$

\author{
أبحاث السرطان في العالم العربي \\ استعراض منشورات من سبعة بلدان بين الفترة 2013-2000
}

$$
\text { رندة ريحي حمادة، سيف البرقان، عبلة السباعي }
$$

ABSTRACT: This review aimed to examine trends in cancer research in the Arab world and identify existing research gaps. A search of the MEDLINE ${ }^{\circledR}$ database (National Library of Medicine, Bethesda, Maryland, USA) was undertaken for all cancer-related publications published between January 2000 and December 2013 from seven countries, including Bahrain, Kuwait, Iraq, Lebanon, Morocco, Palestine and Sudan. A total of 1,773 articles were identified, with a significant increase in yearly publications over time $(P<0.005)$. Only $30.6 \%$ of the publications included subjects over the age of 50 years old. There was a dearth of cross-sectional/correlational studies (8.8\%), randomised controlled trials (2.4\%) and systematic reviews/meta-analyses (1.3\%). Research exploring cancer associations mainly considered social and structural determinants of health (27.1\%), followed by behavioural risk factors (14.1\%), particularly tobacco use. Overall, more cancer research is needed in the Arab world, particularly analytical studies with high-quality evidence and those focusing on older age groups and associations with physical activity and diet.

Keywords: Chronic Diseases; Cancer; Research; Publications; Arab World.

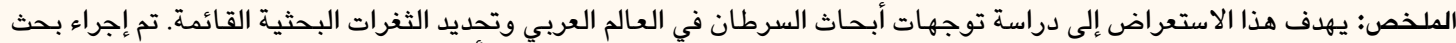

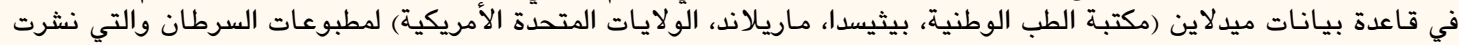

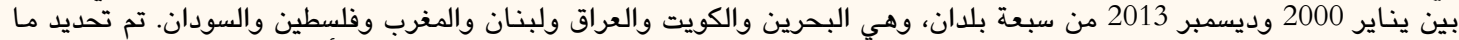

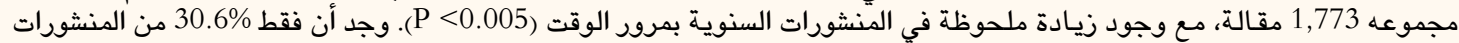

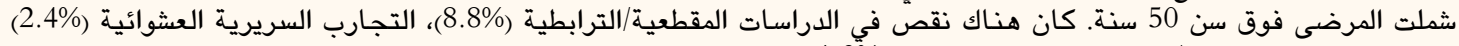

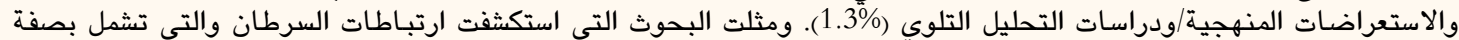

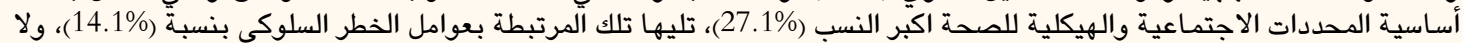

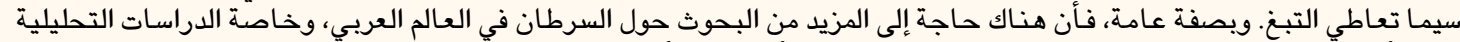

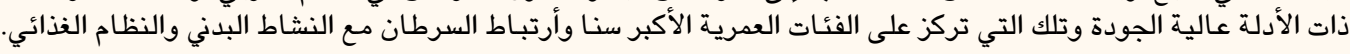

$$
\text { الكلمات المفتاحية: الأمراض المزمنة؛ سرطان؛ بحوث؛ المنشورات؛ العالم العربي. }
$$

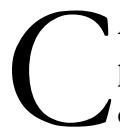
ancer presents a global public health problem and extensively impacts healthcare costs. $^{1-3}$ In 2013, there were 14.9 million new cancer cases and 8.2 million cancer-attributable deaths; in addition, global cancer mortality increased by $25.0 \%$ from 1990 , with a projected incidence of 23.6 million cases/year by 2030., ${ }^{1,2,4}$ The burden of cancer is disproportionately greater in countries with a low-to-medium human development index, with approximately $70.0 \%$ of all cancer deaths and $60.0 \%$ of disability-adjusted life years occurring in developing countries. ${ }^{2-6}$ Moreover, nine of the 10 countries with the highest age-standardised female cancer mortality rates worldwide are developing nations. ${ }^{3}$

Although many Western countries have rapidly established national and regional cancer control initiatives, the most vulnerable regions for cancer mortality-such as those in the Arab world-have yet to institute clear or reliable cancer resources. ${ }^{7-9}$ For example, there are few population-based cancer registries in Arab countries, with only 5.0\% of Asian populations and $2.0 \%$ of African populations reporting high-quality incidence data in comparison to cancer registries in Australia and New Zealand, which cover $100 \%$ of their total populations. ${ }^{10}$ Additionally, while $80.0 \%$ of countries in the Eastern Mediterranean region have national cancer control policies, only $45.0 \%$ are operational. ${ }^{11}$ In general, healthcare systems in this region are inadequately equipped to deal with chronic diseases, such as cancer, which necessitate long and costly management facilities, especially in countries with political unrest. 
The commonest cancers worldwide for both genders are breast, lung, colorectal, prostate and stomach cancers. ${ }^{3,4,10}$ In the Middle Eastern and North African (MENA) region, similar trends exist, although bladder and stomach cancers constitute the fifth and sixth most common forms of cancer, regardless of gender. ${ }^{3}$ Among Gulf Cooperation Council countries, the most frequent cancers among males are colorectal cancer, non-Hodgkin's lymphomas, lung cancer and liver cancer, while breast cancer is most common among females, followed by thyroid and colorectal cancers and non-Hodgkin's lymphomas. ${ }^{12,13}$ However, despite similar sociocultural environments, cancer incidence rates vary widely within and between Arab populations. ${ }^{14}$ Cancer research is vital for the development of effective, specific and sustainable healthcare policies. Within this context, this article aimed to examine the landscape of cancer research in seven selected Arab countries to identify publication trends as well as gaps and opportunities for future research.

\section{Methods}

A scoping review methodology was used to analyse articles published on non-communicable diseases (NCDs) from Bahrain, Kuwait, Iraq, Lebanon, Morocco, Palestine and Sudan. ${ }^{15}$ These seven countries were selected to represent various stages of demographic and epidemiological transition as well as socioeconomic development. The selected countries were categorised into low-middle income countries (LMICs), upper-middle income countries (UMICs) and high-income countries (HICs) based on their gross domestic product (GDP); as such, Sudan, Palestine and Morocco were classified as LMICs while Iraq and Lebanon were designated as UMICs and Bahrain and Kuwait as HICs. ${ }^{16}$ Four conditions were defined as NCDs, namely cardiovascular diseases, cancer, chronic obstructive pulmonary disease and type 2 diabetes mellitus.

The MEDLINE ${ }^{\circledR}$ database (National Library of Medicine, Bethesda, Maryland, USA) was used to systematically search for all NCD-related articles published between January 2000 and December 2013. The search strategy consisted of a combination of key terms related to the four NCD conditions and their associated risk factors. Further details on the search strategy have been published elsewhere using the same dataset. ${ }^{17}$ Briefly, several reviewers independently assessed each article to determine whether it met the inclusion criteria and was relevant. Articles were included if the content addressed NCDs and/or NCD risk factors, was related to human health or health systems and if the article pertained to or originated from one of the seven selected Arab countries. Any discrepancies in the selection of articles were systematically addressed and discussed in a group before a communal decision was reached.

During the initial database search, 9,162 publications were identified, of which 1,212 were duplicates and were removed. Subsequently, 3,466 publications were excluded as they were deemed irrelevant based on screening of the abstract and title and another 708 papers were excluded as they did not meet the inclusion criteria upon reading the full text. Finally, 2,003 other NCD-related articles were excluded as the main outcome was not cancer. This yielded a total of 1,773 cancer-related publications which were included in the final analysis. The full text and abstract of each article was downloaded, if available, including article-specific information (e.g. journal title, year of publication, authors' names and first authors' affiliation details).

Data regarding the research setting, design and content were independently extracted from each article using a standardised form. The research setting was described according to whether it was laboratory-, hospital/clinic-, patient- or populationbased. Publications were classified into four major types: descriptive (i.e. case reports, case series and correlational/cross-sectional studies), analytic (i.e. cohort studies, case-control studies and randomised control trials $[\mathrm{RCTs}]$ ), reviews (i.e. descriptive literature reviews and systematic reviews/metaanalyses) and laboratory studies (i.e. pathology/in vivo studies). Studies with qualitative and/or mixed methods and commentary articles/letters to editors were given a separate grouping as there were very few of these types of articles.

Risk factors identified during a review of the content of each article were grouped into broad categories, including social/structural determinants of health (e.g. demographic/socioeconomic variables or access to care/health system research), behavioural/lifestyle-related variables (e.g. tobacco and alcohol use, nutrition/diet, salt intake and physical activity) and physiological factors (e.g. anthropometric measurements, obesity, diabetes, hypertension or cholesterol). Other information was also noted, including the age group of the subjects, whether the article had a public health focus as opposed to a clinical one, whether the authors' affiliations indicated collaborations with non-academic individuals/institutions, such as governmental or nongovernmental organisations (NGOs), and the scope of the journals (either local, regional or international). First authors' affiliations were analysed according to 
A

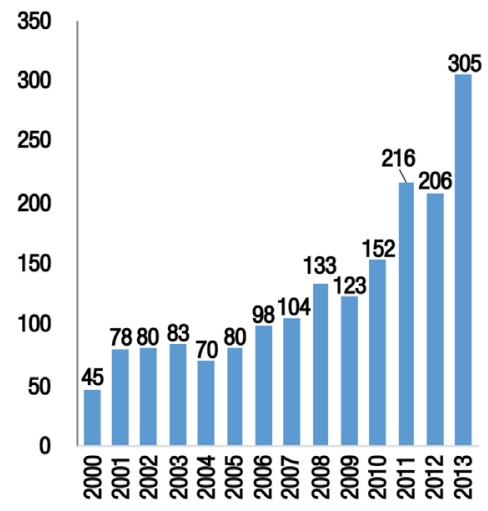

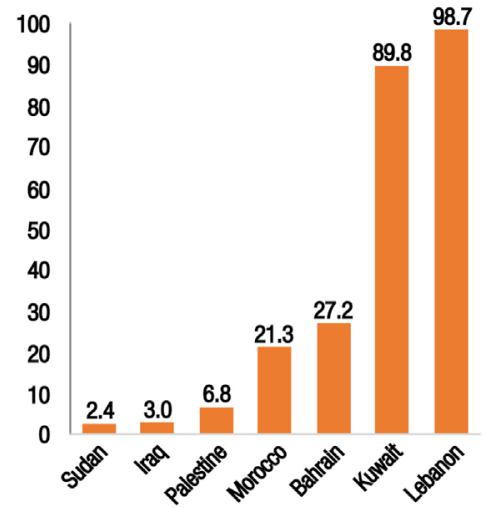

Figure 1: Number of cancer publications from selected Arab countries between 2000-2013 (A) per year and (B) per million people per country $(\mathrm{N}=1,773)$.

whether the author was associated with a clinical or academic institution.

In order to eliminate the effect of more populous countries, the publication rate per million people was estimated for each country. Results were presented using numbers and percentages. The trends over time were first assessed for all publications and then stratified by country and article type. All data were recorded in a database before being transferred to the Statistical Package for the Social Sciences (SPSS), Version 22.0 (IBM Corp., Armonk, New York, USA) for statistical analysis. Correlation regression, Chisquared and linear regression tests were used, as appropriate. A $P$ value of $<0.050$ was considered statistically significant.

\section{Results}

Of the 1,773 publications identified, 1,611 (90.9\%) were published in international journals, with 81 (4.6\%) articles each published in regional and local journals, respectively. The proportion of international publications out of the total number of publications per country varied, with $98.6 \%$ in Morocco, $93.1 \%$ in Palestine, $89.8 \%$ in Lebanon, $85.5 \%$ in Kuwait, $85.3 \%$ in Sudan, $83.8 \%$ in Bahrain and $66.0 \%$ in Iraq. The majority of the articles were published in English ( $\mathrm{n}=1,368 ; 77.2 \%)$. Of the articles published in other languages, most were from Morocco and were published in French (55.0\%).

A significant positive linear relationship was observed between year and total number of publications $\left(\mathrm{R}^{2}=0.791 ; P<0.005\right)$, with a $132.9 \%$ increase in publications during the last seven years of the review period compared to the first seven years [Figure 1A]. Of the total number of publications, 723 were from Morocco (40.8\%), 449 were from Lebanon (25.3\%), 337 were from Kuwait (19.0\%), 103 were from Iraq (5.8\%), 95 were from Sudan (5.4\%), 37 were from Bahrain (2.1\%) and 29 were from Palestine (1.6\%). However, Lebanon had the highest publication rate per million people (98.7), followed by Kuwait (89.8), Bahrain (27.2), Morocco (21.3), Palestine (6.8), Iraq (3.0) and Sudan (2.4), with a significant difference across countries $(P<0.001)$ [Figure 1B]. With the exception of Iraq and Sudan, the highest proportions of articles in all countries were published in 2013, with the greatest increase observed in Palestine [Figure 2].

In total, the most common types of research published were case reports (34.8\%) and laboratory studies (15.5\%), whereas very few systematic reviews/ meta-analyses (1.3\%) were published. Over half of all publications $(51.0 \%)$ were descriptive in design, with Morocco having the highest proportion of descriptive articles out of their total number of publications (72.3\%). Articles with an analytical research design formed $18.2 \%$ of the publication pool, with Iraq having the highest proportion out of their total number of publications (29.1\%). Of the 43 RCTs

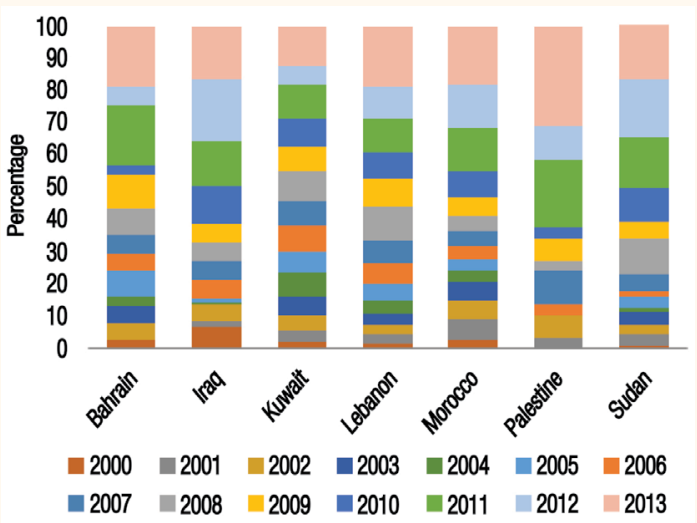

Figure 2: Percentage of yearly publications out of the total number of cancer publications from selected Arab countries between 2000-2013 ( $\mathrm{N}=1,773)$. 
published (2.4\%), 55.8\% were from Lebanon, $27.9 \%$ were from Kuwait, 7.0\% were from Morocco and 4.7\% each were from Iraq and Sudan. Of the total publications per country, Bahrain and Palestine had the highest proportions of reviews $(27.0 \%$ and $24.1 \%$, respectively) while Palestine had the highest proportion of laboratory studies (41.4\%) [Table 1].

A significant positive linear relationship was noted between the year and RCT publications $\left(R^{2}=0.319\right.$; $P=0.035)$. When grouping countries by GDP category, LMICs more frequently published descriptive research (68.7\% versus $35.8 \%$, respectively) and less frequently published laboratory studies $(8.5 \%$ versus $25.9 \%$, respectively) or analytical research (13.9\% versus 22.7\%, respectively) compared to HICs $(P<0.001)$.

The majority of publications with ascertained settings were hospital-based (79.8\%), followed by laboratory-based (14.1\%) and population-based (5.1\%) articles. According to the first author's affiliations, there was an overall comparable proportion of associations with hospital (41.6\%) and academic (40.3\%) institutions. However, Palestine and Sudan had the highest proportions of first authors affiliated with universities (86.2\% and $81.1 \%$, respectively), while Morocco had the lowest (16.3\%); the corresponding percentages for Iraq, Kuwait, Lebanon and Bahrain were $77.7 \%, 54.6 \%, 48.8 \%$ and $32.4 \%$, respectively. Collaboration with non-academic NGO and governmental organisations was evident in $6.0 \%$ of all publications. Articles published in collaboration with non-academic authors were most prevalent from Sudan (22.1\%), followed by Bahrain (16.2\%), Iraq (7.8\%), Kuwait (7.1\%), Palestine (6.9\%), Lebanon (4.5\%) and Morocco (3.5\%). Of the total number of publications, $16.6 \%$ had a public health focus with 51.7\% in Palestine, 42.1\% in Sudan, 35.1\% in Bahrain, $21.1 \%$ in Kuwait, $18.4 \%$ in Iraq, $14.9 \%$ in Lebanon and 9.7\% in Morocco.

Table 1: Cancer publications from selected Arab countries between 2000-2013 by research design and country $(\mathrm{N}=1,773)$

\begin{tabular}{|c|c|c|c|c|c|c|c|c|}
\hline \multirow[t]{2}{*}{ Research design } & \multicolumn{8}{|c|}{ n (\%) } \\
\hline & Bahrain & Iraq & Kuwait & Lebanon & Morocco & Palestine & Sudan & Total \\
\hline \multicolumn{9}{|l|}{ Descriptive } \\
\hline Case reports & $12(32.4)$ & $8(7.8)$ & $79(23.4)$ & $116(25.8)$ & $396(54.8)$ & $1(3.4)$ & $4(4.3)$ & $616(34.8)$ \\
\hline Case series & $0(0.0)$ & $6(5.8)$ & $9(2.7)$ & $15(3.3)$ & $88(12.2)$ & $0(0.0)$ & $13(13.8)$ & $131(7.4)$ \\
\hline $\begin{array}{l}\text { Cross-sectional/ } \\
\text { correlational studies }\end{array}$ & $5(13.5)$ & $19(18.4)$ & $29(8.6)$ & $28(6.2)$ & $38(5.2)$ & $4(13.8)$ & $33(35.1)$ & $156(8.8)$ \\
\hline \multicolumn{9}{|l|}{ Analytical } \\
\hline Case-control studies & $1(2.7)$ & $11(10.7)$ & $17(5.0)$ & $13(2.9)$ & $26(3.6)$ & $1(3.4)$ & $16(17.0)$ & $85(4.8)$ \\
\hline Cohort studies & $6(16.2)$ & $17(16.5)$ & $49(14.5)$ & $53(11.8)$ & $64(8.9)$ & $3(10.3)$ & $2(2.1)$ & $194(11.0)$ \\
\hline RCTs & $0(0.0)$ & $2(1.9)$ & $12(3.6)$ & $24(5.3)$ & $3(0.4)$ & $0(0.0)$ & $2(2.1)$ & $43(2.4)$ \\
\hline \multicolumn{9}{|l|}{ Reviews } \\
\hline $\begin{array}{l}\text { Systematic reviews/ } \\
\text { meta-analyses }\end{array}$ & $1(2.7)$ & $3(2.9)$ & $2(0.6)$ & $9(2.0)$ & $5(0.7)$ & $3(10.3)$ & $0(0.0)$ & $23(1.3)$ \\
\hline $\begin{array}{l}\text { Descriptive literature } \\
\text { reviews }\end{array}$ & $9(24.3)$ & $4(3.9)$ & $42(12.5)$ & $90(20.0)$ & $39(5.4)$ & $4(13.8)$ & $12(12.8)$ & $200(11.3)$ \\
\hline \multicolumn{9}{|l|}{ Laboratory studies } \\
\hline $\begin{array}{l}\text { Pathology/in vivo } \\
\text { studies }\end{array}$ & $3(8.1)$ & $27(26.2)$ & $94(27.9)$ & $80(17.8)$ & $49(6.8)$ & $12(41.4)$ & $10(10.6)$ & $275(15.5)$ \\
\hline \multicolumn{9}{|l|}{ Other } \\
\hline $\begin{array}{l}\text { Commentaries/letters } \\
\text { to the editor }\end{array}$ & $0(0.0)$ & $6(5.8)$ & $4(1.2)$ & $14(3.1)$ & $9(1.2)$ & $1(3.4)$ & $2(2.1)$ & $36(2.0)$ \\
\hline $\begin{array}{l}\text { Qualitative and/ } \\
\text { or mixed methods } \\
\text { studies }\end{array}$ & $0(0.0)$ & $0(0.0)$ & $0(0.0)$ & 7 (1.6) & $5(0.7)$ & $0(0.0)$ & $0(0.0)$ & $12(0.7)$ \\
\hline Total & $37(2.1)$ & $103(5.8)$ & $337(19.0)$ & $449(25.4)$ & $722(40.8)$ & $29(1.6)$ & $94(5.3)$ & $1,771^{*}$ \\
\hline
\end{tabular}


A

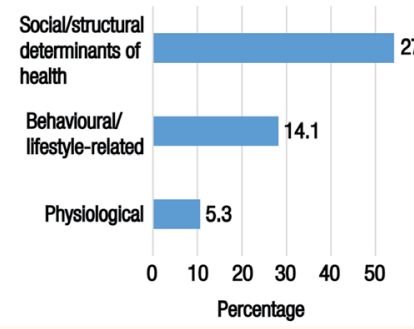

B

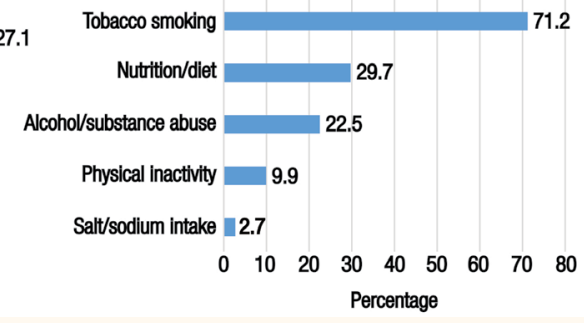

Figure 3: Proportion of (A) overall risk factors and (B) behavioural risk factors identified in cancer publications from selected Arab countries between 2000-2013."

"Percentages do not add up to 100\% as multiple factors were sometimes examined in a single article.

Out of 1,179 publications (66.5\%) involving human subjects, $73.4 \%$ included adult participants aged $\geq 18$ years old and $10.7 \%$ involved all age groups. The most commonly included age group was $18-50$ years $(37.6 \%)$, whereas only $30.6 \%$ of the articles examined older individuals ( $>50$ years old). A total of 780 publications examined determinants of cancer, of which 211 publications (27.1\%) investigated social/ structural determinants of health, 41 articles (5.3\%) examined physiological risk factors and 110 identified behavioural risk factors (14.1\%) [Figure 3A]. Among physiological risk factors, obesity was the most common (65.2\%), followed by hypertension (34.8\%), cholesterol (13.0\%) and metabolic syndrome (4.3\%). The most common behavioural risk factors studied were tobacco use (71.2\%) and nutrition (29.7\%) [Figure 3B].

\section{Discussion}

Although cancer poses a global healthcare burden, research efforts in this field remain limited in many developing countries. To the best of the authors' knowledge, this is the first scoping review of cancer research in the Arab world and sheds light on the paucity of cancer publications in this region as well as providing insight into research areas needing greater focus. A consistent increase was observed in cancer research in the selected Arab countries from the beginning of the $21^{\text {st }}$ century until 2013 . However, the total number of publications was considerably lower than in other parts of the world; while the current review identified a total of 1,773 articles published in seven Arab countries over 14 years, there was a yearly average of 10,293 cancer publications in the USA, 9,962 in Europe and 2,225 in Japan between 2000-2008. ${ }^{18}$

The vast difference in research publications from the Arab region could be explained by several factors. First, there are fewer researchers in Arab countries in comparison to Western countries, with Arab researchers in 2013 forming a mere 1.9\% of all researchers worldwide, a decrease from $2.2 \%$ in 1996. ${ }^{19}$ Second, national and regional spending on research and development is relatively modest; in 2013, the regional gross expenditure on research and development (GERD) by all Arab states was USD \$15.5 million, considerably lower than that of the European Union and North America (USD \$282.0 million and USD $\$ 427.0$ million, respectively), and constituting only $1.0 \%$ of total global research expenditures. ${ }^{19}$ In 2011, the HIC nations of Bahrain and Kuwait invested $0.04 \%$ and $0.1 \%$, respectively, of their GDP on GERD, compared to $2.8 \%$ in the USA and $3.3 \%$ in Japan. ${ }^{19}$

Other reasons have also been proposed to explain low research output in the MENA region. Lages et al. reported that conducting research in this region could be challenging due to a lack of access to reliable and valid data, deficiencies in research support infrastructure, language barriers and a lack of networking among researchers. ${ }^{20}$ Political instability has also been hypothesised to affect research publications, as demonstrated in Uganda and Kenya. ${ }^{21-23}$ Unfortunately, political unrest may result in a reduction in funding, massive in- and outmigration, strikes and violence. While no studies have yet systematically investigated the effect of political instability on research production in the Arab world, output trends from the current review revealed a clear drop in cancer-related publications from Iraq, Sudan and Bahrain coinciding with specific periods of civil unrest in these countries. More research is warranted to explore reasons for low cancer research output in the Arab world and the possible effect of political unrest.

While all types of research designs are vital in the field of oncology, the current review noted a scarcity of analytical studies and systematic reviews/ meta-analyses from the selected Arab countries. In addition, it was observed that LMICs were more likely to publish descriptive research, while HICs were more likely to conduct laboratory and analytic research. High-evidence analytical research studies, such as 
RCTs, may be difficult to conduct in LMICs due to weak infrastructure, low research spending and the cultural attitudes of physicians and patients towards clinical research. ${ }^{24-26}$ Currently, RCTs remain the gold standard for analysing healthcare interventions, especially for cancer treatments which are becoming more specific with varying efficacies and side-effect profiles across different ethnic populations. ${ }^{27,28}$ Thus, it is vital that Arab populations be included during drug research and development. Furthermore, health ministries in the Arab world should encourage and facilitate analytical cancer research.

While the incidence of cancer increases with age and occurs predominately in older individuals, patients over the age of 65 years are rarely included in oncology clinical trials. ${ }^{29,30}$ In the current review, the most commonly included age group was $18-50$ years, with those $>50$ years old comprising the minority of subjects. This lack of representation of older age groups may negatively impact cancer treatments for the elderly. ${ }^{31}$ A hesitancy to include older participants could be attributed to perceptions by physicians of a lack of tolerance on the part of older patients, varying drug metabolisms and a lack of evidence of treatment efficacy among this population. ${ }^{31}$ Conducting geriatricspecific studies in the Arab world could therefore provide new insights regarding the diagnosis and treatment of cancer in this population.

Although cancer poses a major public health challenge, surprisingly few of the publications identified in the current review were found to be focused on public health. ${ }^{1,4}$ Primary prevention of cancer through lifestyle modifications is important to reduce the global cancer burden, as an estimated $35 \%$ of cancer deaths may be attributable to modifiable risk factors such as smoking, alcohol use, diet, obesity and unprotected sexual activity. ${ }^{32}$ Of note, the burden of a high body mass index has increased over the last 23 years and is currently the leading risk factor for cancer among women, especially in North and South America and the MENA region. ${ }^{33}$ The prevalence of behavioural risk factors for NCDs is alarmingly high in the Arab region, with overall limited governmental response measures; for example, only Bahrain, Iraq, Morocco and Sudan of the countries included in the present review have established national cancer control policies. ${ }^{34,35}$ Moreover, preventative cancer control policies targeting behavioural risk factors are only present in certain Arab countries; for instance, only Bahrain, Iraq, Lebanon, Morocco and Sudan have operational policies, strategies or action plans in place to reduce the tobacco burden, with Bahrain, Iraq and Sudan also having primary prevention policies for obesity and physical inactivity. ${ }^{35}$ In the current review, behavioural risk factors for cancer were examined in only $14.1 \%$ of publications, with the majority focusing on tobacco use as a sole risk factor and very few examining physical inactivity and salt/sodium intake. Future studies should therefore address diet, obesity and physical inactivity in cancer risk factor epidemiological studies of Arab populations.

Academia is a highly competitive curiositydriven field that is privileged to have a large degree of research freedom, whereas non-academic research may be driven by other factors such as policies and market demands. ${ }^{34,36,37}$ Nevertheless, both sectors are vital for the advancement of clinical research and, in many instances, are complementary. ${ }^{36}$ In the present review, very few research publications involved collaborative efforts between researchers from educational/academic settings and those from NGOs and governmental institutions. While the ultimate responsibility for advancing medical knowledge through research lies on academic institutions, collaboration between academic researchers, the public sector and NGOs is conducive and necessary for the translation of research into action, for instance in terms of national policies and programmes.

The findings of this review need to be considered in the light of certain limitations. The search strategy was restricted to the MEDLINE ${ }^{\circledR}$ database (National Library of Medicine); as such, articles published in local and regional journals were likely excluded, particularly those written in Arabic, which may have led to an underestimation of the total number of published studies from this region. Additionally, electronic searches using specific search terms do not always identify all eligible publications; for example, in a Cochrane review, Hopewell et al. found that an electronic search in the MEDLINE ${ }^{\circledR}$ database (National Library of Medicine) identified only 55\% of actual RCTs compared to hand-searching, which identified $92-100 \%{ }^{38}$ It is also important to note that the present review drew on data from only seven Arab countries and, while these countries were selected to represent a range of demographic characteristics, epidemiological transitions and political stability, the current findings therefore cannot be generalised to the entire Arab region.

\section{Conclusion}

Cancer research is increasing in the Arab world. However, the total research output remains low when compared to other regions. The current review identified several gaps in research, including a deficiency in research involving elderly populations and investigating specific risk factors such as diet 
and physical activity. In addition, there was a dearth of systematic reviews/meta-analyses and analytical studies; further studies are therefore recommended to identify reasons for the scarcity of these types of research in this region. Furthermore, increased collaboration between NGOs, governmental agencies and academic institutions is key for the implementation of national evidence-based healthcare policies specific to cancer control. Cancer researchers and funding agencies are encouraged to consider the gaps identified in this review in order to better guide future cancer research.

\section{ACKNOWLEDGEMENTS}

The authors wish to acknowledge the help of the NCD Scoping Review Working Group of the Faculty of Health Sciences at the American University of Beirut, Beirut, Lebanon. In particular, the authors thank Dr. Sawsan Abdulrahim, Dr. Farah Naja, Dr. Shadi Saleh and Dr. Samer Jabbour, as well as the various research assistants involved, especially

Mr. Anthony Rizk.

\section{FUNDING}

This work was funded with the aid of a grant from the International Development Research Centre, Ottawa, Ontario, Canada (grant \#106981-00).

\section{References}

1. NCD Alliance. Cancer burden. From: www.ncdalliance.org/ cancer Accessed: Jan 2017.

2. Terzic A, Waldman S. Chronic diseases: The emerging pandemic. Clin Transl Sci 2011; 4:225-6. doi: 10.1111/j.1752-8062.2011. 00295.x.

3. International Agency for Research on Cancer. GLOBOCAN 2012: Estimated cancer incidence, mortality and prevalence worldwide in 2012. From: http://globocan.iarc.fr/Pages/fact sheets_population.aspx Accessed: Jan 2017.

4. Global Burden of Disease Collaboration; Fitzmaurice C, Dicker D, Pain A, Hamavid H, Moradi-Lakeh M, et al. The global burden of cancer 2013. JAMA Oncol 2015; 1:505-27. doi: 10.1001/ jamaoncol.2015.0735.

5. Bray F, Jemal A, Grey N, Ferlay J, Forman D. Global cancer transitions according to the Human Development Index (20082030): A population-based study. Lancet Oncol 2012; 13:790801. doi: 10.1016/S1470-2045(12)70211-5

6. World Health Organization Regional Office for Africa. Building capacity in cancer registration. From: www.afro. who.int/en/clusters-a-programmes/dpc/non-communicablediseasesmanagementndm/npc-features/3221-buildingcapacity-in-cancer-registration.html Accessed: Jan 2017.

7. European Commission. European Partnership Action against Cancer: Contribution of EU funded research. From: http:// europa.eu/rapid/press-release_MEMO-09-294_en.htm Accessed: Jan 2017.

8. The World Bank. Updated income classifications. From: http:// blogs.worldbank.org/opendata/updated-income-classifications Accessed: Jan 2017.
9. Batouli A, Jahanshahi P, Gross CP, Makarov DV, Yu JB. The global cancer divide: Relationships between national healthcare resources and cancer outcomes in high-income vs. middle- and low-income countries. J Epidemiol Glob Health 2014; 4:115-24. doi: 10.1016/j.jegh.2013.10.004.

10. Ferlay J, Soerjomataram I, Dikshit R, Eser S, Mathers C, Rebelo M, et al. Cancer incidence and mortality worldwide: Sources, methods and major patterns in GLOBOCAN 2012; Int J Cancer 2015; 136:E359-86. doi: 10.1002/ijc.29210.

11. World Health Organization. Cancer control: A global snapshot in 2015. From: www.who.int/cancer/Cancer_Control_Snapshot _in_2015.pdf?ua=1 Accessed: Jan 2017.

12. World Health Organization Regional Office for the Eastern Mediterranean. Cancer registry in the region. From: www.emro. who.int/noncommunicable-diseases/information-resources/ cancer-registry.html Accessed: Jan 2017.

13. Gulf Center for Cancer Control \& Prevention. Ten-year cancer incidence among nationals of the GCC states: 1998-2009. From: www.moh.gov.bh/Content/Files/Publications/GCC\%20 Cancer\%20Incidence\%202011.pdf Accessed: Jan 2017.

14. Salim EI, Moore MA, Al-Lawati JA, Al-Sayyad J, Bazawir A, Bener A, et al. Cancer epidemiology and control in the Arab world: Past, present and future. Asian Pac J Cancer Prev 2009; 10:3-16.

15. Arksey H, O'Malley L. Scoping studies: Towards a methodological framework. Int J Soc Res Methodol 2005; 8:19-32. doi: 10.1080/1364557032000119616.

16. The World Bank. Population, total. From: data.worldbank.org/ indicator/SP.POP.TOTL Accessed: Jan 2017.

17. Jamaluddine Z, Sibai AM, Othman S, Yazbek S. Mapping genetic research in non-communicable disease publications in selected Arab countries: First step towards a guided research agenda. Health Res Policy Syst 2016; 14:81. doi: 10.1186/s129 61-016-0153-9.

18. Micheli A, Di Salvo F, Lombardo C, Ugolini D, Baili P, Pierotti AM. Cancer research performance in the European Union: A study of published output from 2000 to 2008. Tumori 2011; 97:683-9. doi: $10.1700 / 1018.11081$.

19. United Nations Educational, Scientific and Cultural Organization Instutute for Statistics. Science, technology and innovation: Gross domestic expenditure on R\&D (GERD), GERD as a percentage of GDP, GERD per capita and GERD per researcher. From: http://data.uis.unesco.org/?queryid=74 Accessed: Jan 2017.

20. Lages CR, Pfajfar G, Shoham A. Challenges in conducting and publishing research on the Middle East and Africa in leading journals. Int Mark Rev 2015; 32:52-77. doi: 10.1108/IMR-122014-0374.

21. Mokdad AH, Forouzanfar MH, Daoud F, El Bcheraoui C, Moradi-Lakeh M, Khalil I, et al. Health in times of uncertainty in the Eastern Mediterranean region, 1990-2013: A systematic analysis for the Global Burden of Disease Study 2013. Lancet Glob Health 2016; 4:e704-13. doi: 10.1016/S2214109X(16)30168-1.

22. Bakamanume BB. Political instability and health services in Uganda, 1972-1997. East Afr Geogr Rev 1998; 20:58-71. doi: 10.1080/00707961.1998.9756267.

23. House DR, Marete I, Meslin EM. To research (or not) that is the question: Ethical issues in research when medical care is disrupted by political action - A case study from Eldoret, Kenya. J Med Ethics 2016; 42:61-5. doi: 10.1136/medethics2013-101490.

24. Devasenapathy N, Singh K, Prabhakaran D. Conduct of clinical trials in developing countries: A perspective. Curr Opin Cardiol 2009; 24:295-300. doi: 10.1097/HCO.0b013e32832af21b. 
25. Lang TA, White NJ, Tran HT, Farrar JJ, Day NP, Fitzpatrick R, et al. Clinical research in resource-limited settings: Enhancing research capacity and working together to make trials less complicated. PLoS Negl Trop Dis 2010; 29:e619. doi: 10.1371/ journal.pntd.0000619.

26. Mbuagbaw L, Thabane L, Ongolo-Zogo P, Lang T. The challenges and opportunities of conducting a clinical trial in a low resource setting: The case of the Cameroon mobile phone SMS (CAMPS) trial, an investigator initiated trial. Trials 2011; 12:145. doi: 10.1186/1745-6215-12-145.

27. Domanski M, McKinlay S. Successful Randomized Trials: A handbook for the 21st century. Philadelphia, Pennsylvania, USA: Lippincott Williams \& Wilkins, 2008. P. 13.

28. O'Donnell PH, Dolan ME. Cancer pharmacoethnicity: Ethnic differences in susceptibility to the effects of chemotherapy. Clin Cancer Res 2009; 15:4806-14. doi: 10.1158/1078-0432.CCR09-0344.

29. Unger JM, Coltman CA Jr, Crowley JJ, Hutchins LF, Martino S, Livingston RB, et al. Impact of the year 2000 Medicare policy change on older patient enrollment to cancer clinical trials. J Clin Oncol 2006; 24:141-4. doi: 10.1200/JCO.2005.02.8928.

30. Kimmick GG, Peterson BL, Kornblith AB, Mandelblatt J, Johnson JL, Wheeler J, et al. Improving accrual of older persons to cancer treatment trials: A randomized trial comparing an educational intervention with standard information - CALGB 360001. J Clin Oncol 2005; 23:2201-7. doi: 10.1200/JCO.2005. 01.222 .

31. Denson AC, Mahipal A. Participation of the elderly population in clinical trials: Barriers and solutions. Cancer Control 2014; 21:209-14.
32. Danaei G, Vander Hoorn S, Lopez AD, Murray CJ, Ezzati M; Comparative Risk Assessment Collaborating Group (Cancers). Causes of cancer in the world: Comparative risk assessment of nine behavioural and environmental risk factors. Lancet 2005; 366:1784-93. doi: 10.1016/S0140-6736(05)67725-2.

33. GBD 2015 Risk Factors Collaborators. Global, regional, and national comparative risk assessment of 79 behavioral, environmental and occupational, and metabolic risks or clusters of risks, 1990-2015: A systematic analysis for the Global Burden of Disease Study 2015. Lancet 2016; 388:1659-1724. doi: 10.1016/S0140-6736(16)31679-8.

34. Rahim HF, Sibai A, Khader Y, Hwalla N, Fadhil I, Alsiyabi H, et al. Non-communicable diseases in the Arab world. Lancet 2014; 383:356-67. doi: 10.1016/S0140-6736(13)62383-1.

35. World Health Organization. Cancer country profiles 2014. From: www.who.int/cancer/country-profiles/en/ Accessed:Jan 2017.

36. Leung I. Research in academic and non-academic institutions. From: www.cuhk.edu.hk/clear/rs/research_in_institutions.pdf Accessed: Jan 2017.

37. Brew A, Lucas L. Academic Research and Researchers. Berkshire, UK: Open University Press, 2009. Pp. 13-14.

38. Hopewell S, Clarke M, Lefebvre C, Scherer R. Handsearching versus electronic searching to identify reports of randomized trials. Cochrane Database Syst Rev 2007; 2:MR000001. doi: 10.1002/14651858.MR000001.pub2. 